\title{
HEMANGIOBLASTOMA DE LOCALIZAÇÃO SUPRA-TENTORIAL
}

\author{
MURILO CORTES DRUMMOND* \\ JOAO JOSE DE ARAUJO MOURA FILHO ** \\ SUELI ALVES DE ANDRADE***
}

Os hemangioblastomas do sistema nervoso central são catalogados como neoplasias vasculares benignas, vestígios mesodérmicos implantados no tecido nervoso durante o terceiro mês de evolução fetal. Bailey e col. 1,2 admitiam que os hemisférios cerebrais não seriam sede de neoplasias desta natureza; contudo Russel e Rubinstein 5 descreveram casos de lesões no cérebro. Mais recentemente vários trabalhos se reportam à ocurrência de localizaçōes cerebrais ${ }^{4}$. Os casos raros de localização supra-tentorial se referem a tumorações únicas; entretanto, em 1971 Ishwar ${ }^{3}$ relatou caso de localização supra-tentorial múltipla.

\section{OBSERVAÇAO}

M.C.P.L., sexo masculino, branco, 41 anos de idade, militar, internado em 12-08-1974 (Reg. 19.121) com história pregressa de 8 anos, em que a referência maior era de cefaléia frontal com irradiaçăo para o globo ocular esquerdo. Um ano antes da internaçăo o paciente notou diminuiçăo da fenda palpebral esquer àa e impotência sexual. Nos 20 dias que precederam à internação agravaram-se os sintomas, completando-se a ptose palpebral, generalizando-se a intensa e permanente cefaléia, com a ocurrência de vertigens e vômitos. Exame fisico - Paciente em bom estado geral sem denotar maior preocupaçăo com os sintomas apresentados. Pressão arterial 160/90; pulso $68 \mathrm{p} / \mathrm{m}$. Exame clínico geral sem anormalidajes. Exame neurologico - Ptose palpebral à esquerda, pupila esquerda năo reagente à fotoestimulaçăo, papiledema ả esquerda. Linguagem lenta e hesitante e, em algumas ocasiões, com ligeira disartria. Psiquismo sem alteraçăo. Orientaçăo temporo-espacial normal. Exames complementares - A gamaencefalografia mostrou captação na base do lobo frontal e ponta do lobo temporal esquerdo (Fig. 1). A angiografia por punçăo percutánea da carótida esquerda e compressão da carótida direita confirmou o traçado gamaencefalográfico (Fig. 2).

Intervenção cirúrgica - Craniotomia osteoplástica fronto-temporal à esquerda mostrou grande massa tumoral de coloraçăo vinhosa escura e consistência firme, comprometen to a base do lobo frontal e estendendo-se para a regiăo mesocefálica. $O$ tumor foi removido parcialmente face à abundante hemorragia e impossibilidade de determinaçăo de sua real extensåo. Pós-operatório sem anormalidałes nas primeiras 24 horas, ocorrendo, depois, alterações cardio-respiratórias e óbito.

Exame anatomo-patológico (no 1729) - A massa tumoral observada na necrópsia (no 117) era esférica, medindo $6 \mathrm{~cm}$ de diâmetro, localizada próxima do andar anterior da base do cérebro (Fig. 3), de aspecto cistóide com densa cápsula elástica, de cor esbranquiçada, de espessura variável entre 3 a $4 \mathrm{~mm}$. Foi verificađa grande quanti-

Clínica Neurocirúrgica do Centro Médico Naval Marcilio Dias: " Chefe; * Assistente; * Residente. 

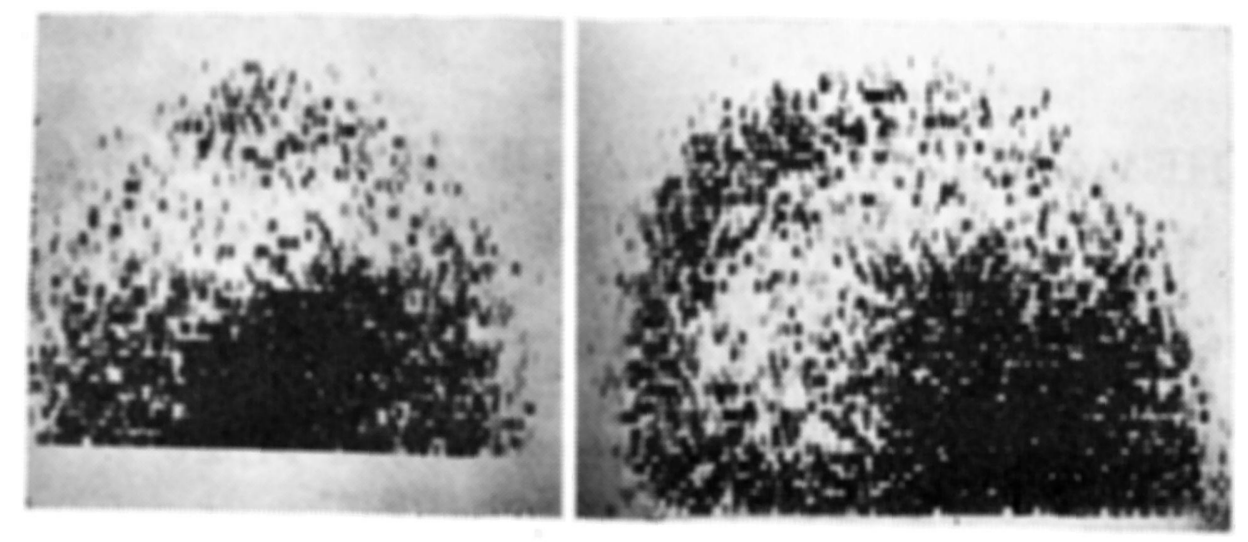

Fig. 1 - M.C.P.L. Gamaencefalografia: captacáo na base do polo frontal e ponta do lobo temporal.

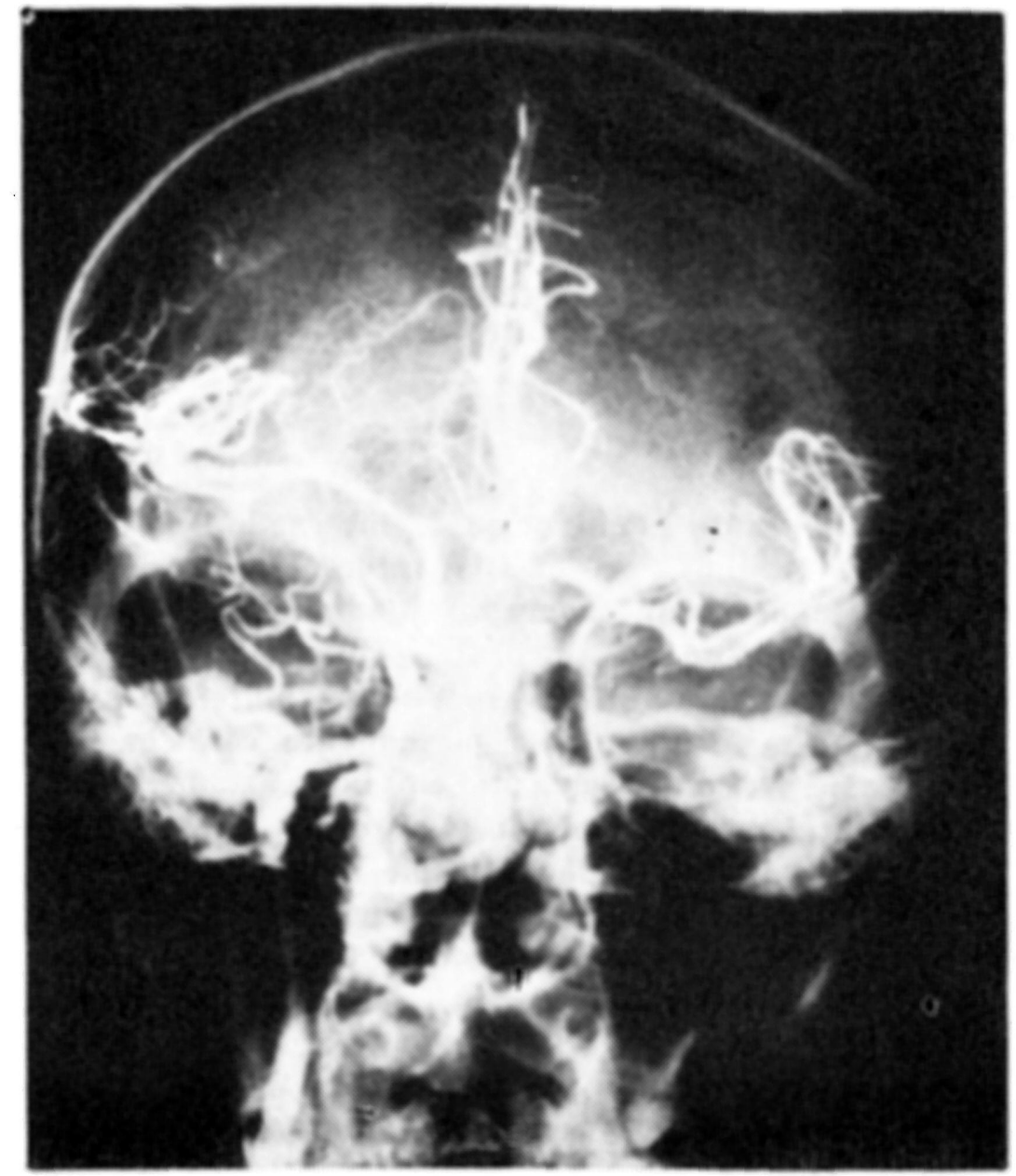

Fig. 2 - Caso M. C. P. L. Carotidoangiografia: levantamento da cerebral média e desvio da cerebral anterior esquerda.

dade de coágulos intracisticos lateralmente à massa tumoral e vários fragmentos de parede com aspecto sólido, mostrando ainda a existência de numerosos vasos imbricados csterna e internamente na massa neoplástica. O tumor avançava em direção à sela turca e às azas do esfenó:de onde ocasionava corrosão. A microscopia revelou (Fig. 4): as lâminas obtidas na parte sólida do tumor mostram tratar-se de neoplasia de tipo vascular formada de células que lembram as células epiteliais, com citoplasma intensamente corado pela eosina, com núcleo vesiculoso, com um ou dois nucléolos, forrando grandes lagos sanguíneos; em outros lugares foram encontradas células mais claras cujo citoplasma vesiculoso lembrava células xantelasmizadas; foram encontradas traves de tecido fibroso dividindo o tumor, alternando-se com lagos sanguíneos, tecido hialino e fibrina; havia alguns vasos com paredes hialinizadas e formação de vasos anastomozados a partir de células tumorais. $O$ aspecto angioblástico da neoplasia é bem evidente. 
As coloraçóes pelo Mallory e pelo Masson destacam as cápsulas fibrosas e o pouco estroma no parênquima. As coloraç̋es para reticulina mostraram fina rede reticular entre os lagos sanguíneos e as células tumorais. A neoplasia era de tipo celular misto com estroma abundantemente vascularizado.

\section{COMHNTARIOS}

A localização dos hemangioglastomas encefálicos se faz preferentemente no cerebelo e no $4^{\circ}$ ventrículo, sendo rara nos hemisférios cerebrais. Em face da raridade da localização nos hemisférios cerebrais julgamos oportuno registrar o presente caso, como contribuição ao estudo dos referidos tumores.

\section{RESUMO}

Os autores tecem considerações gerais sobre os hemangioblastomas e apresentam um caso raro de localização supra-tentorial.

\section{SUMMARY}

Supra-tentorial hemangioblastoma: a case report

A case of hemangioblastoma with supra-tentorial localization is reported. General considerations are made.

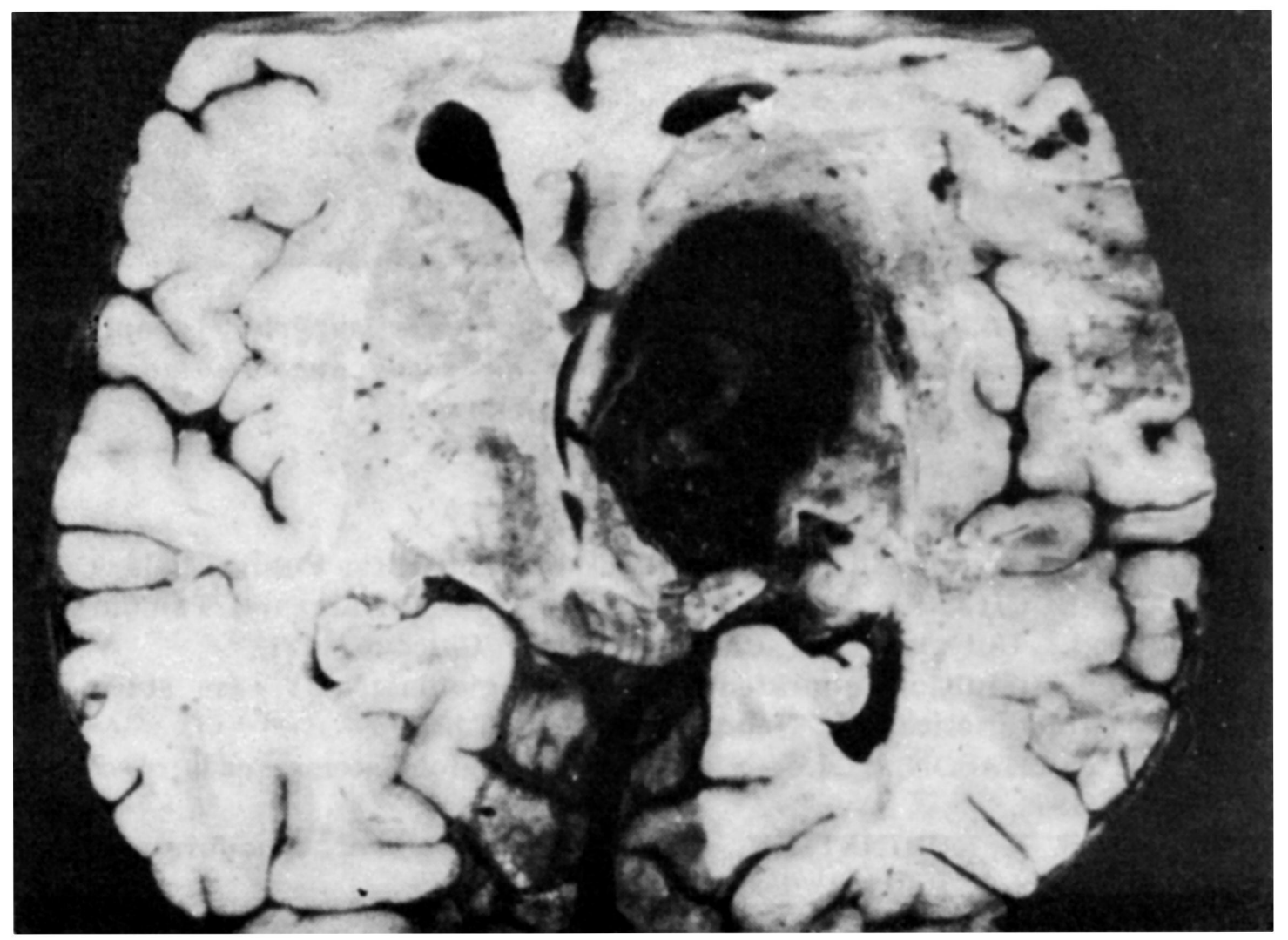

Fig. 3 - Caso M.C.P.L. Pega anatomica mostrando a massa tumoral. 

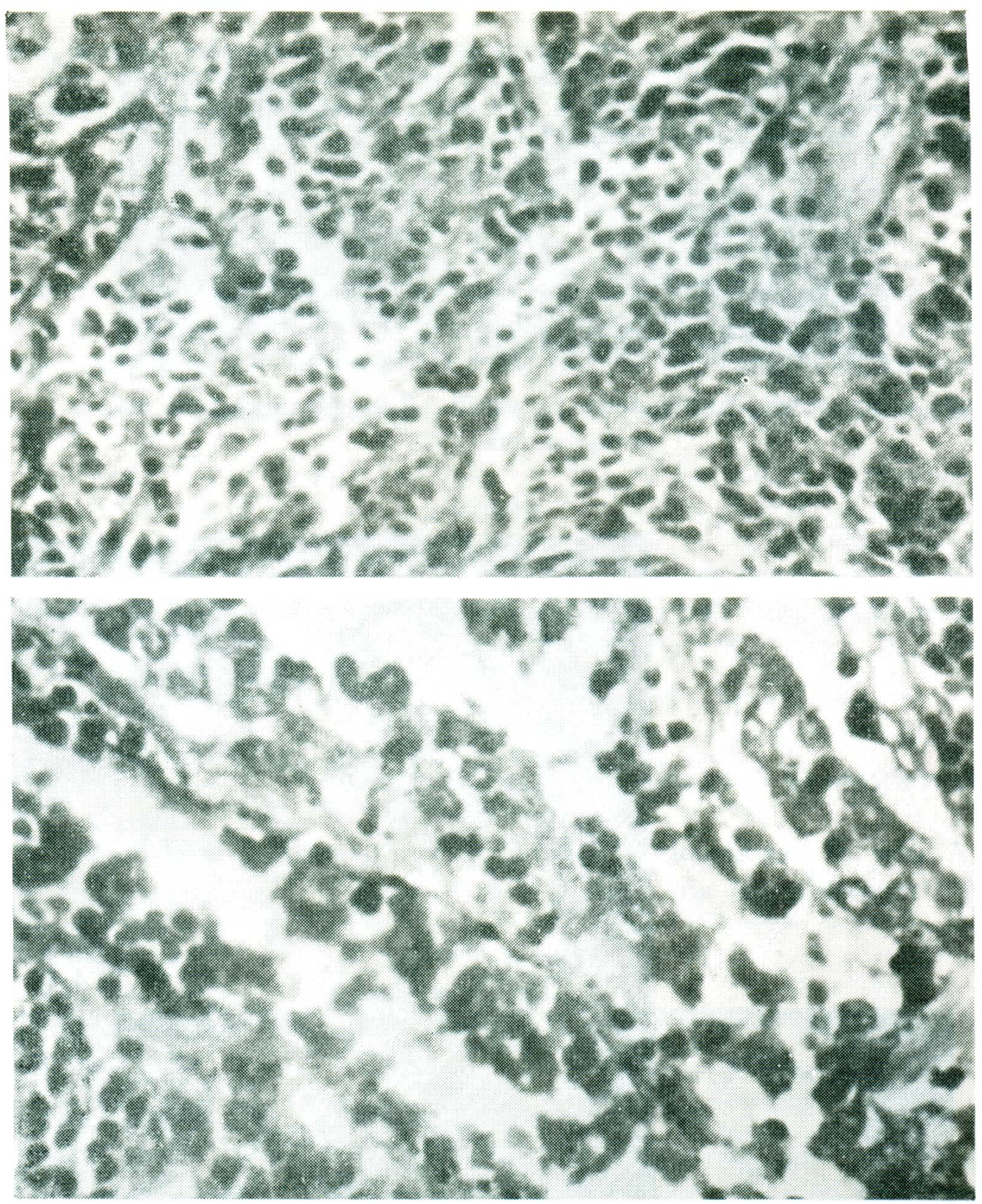

Fig. 4 - Caso M.C.P.L. Exame microscópico: na parte superior neoplasia de tipo vascular; na parte inferior, formação de vasos anastomozados a partir de células tumorais.

\section{REFERENCIAS}

1. BAILEY, P. - Intracranial Tumours. Blackwell Scientific Publications, Oxford, 1947.

2. BAILEY, P.; BUCHANAN, D. N. \& BUCY, P. C. - Intracranial Tumours of Infancy and Childhood. University of Chicago Press, Chicago, 1948.

3. ISHWAR, S. - Multiple supratentorial hemangioblastoma: case study and ultrastructural characteristics. J. Neurosurg. 35:396, 1966.

4. RIVERA, E. \& CHASON, J. I. - Cerebral hemangioblastoma: case report. J. Neurosurg. $25: 452,1966$.

5. RUSSEL, D. S. \& RUBINSTEIN, I. J. - Pathology of Tumours of the Nervous System. E. Arnold, London, 1963. 